\title{
Subjective and objective evaluation of response to radiotherapy after different radiotherapy dose - fraction schemes in osteolytic bone metastases
}

\section{Osteolitik kemik metastazlarında farklı radyoterapi doz-fraksiyon şemaları sonrasında radyoterapiye yanıtın sübjektif ve objektif değerlendirmesi}

\author{
Fatih Göksel ${ }^{1}$, Müge Akmansu² \\ ${ }^{1}$ SBÜ Dr. Abdurrahman Yurtarslan Ankara Onkoloji Eğitim ve Araştırma Hastanesi, Radyasyon Onkolojisi \\ Kliniği, Ankara \\ ${ }^{2}$ Gazi Üniversitesi Tıp Fakültesi Radyasyon Onkolojisi Anabilim Dalı, Ankara
}

Dergiye Ulaşma Tarihi:06.01.2019 Dergiye Kabul Tarihi:14.01.2019 Doi: 10.5505/aot.2019.56833

\section{ÖZET}

GÍRIŞ ve AMAÇ: Osteolitik kemik metastazlı otuzdört hasta iki farklı $10 \mathrm{fr} \times 3$ Gy ve 5 fr $\times 4$ Gy'lik dozfraksiyon şeması sonrası, tedavi cevabı yönünden kemik mineral dansitesi ve ağrı yanıtı yönünden değerlendirmek için çalışmaya alındı.

YÖNTEM ve GEREÇLER: Hastaların 18'i $10 \mathrm{fr} \times 3$ Gy'lik ve 16's1 $5 \mathrm{fr} \times 4$ Gy'lik radyoterapi tedavi kollarına alınmıştır. Palyatif ağrı tedavisi etkinliğinin değerlendirilmesinde hastanın kendi değerlendirmesi esas alınılarak; 1. gün'den 15. güne kadar günlük, son olarak 45. gün olmak üzere VAS ağrı skalası yönünden değerlendirildi. BMD tedavi öncesi ve tedaviden sonraki 6. ay olmak üzere DXA (dual enerji X-ray absopsiyometri) ile iki kez ölçüldü.

BULGULAR: Ağrının cevabında iki farklı doz-fraksiyon şemasında da zamanla istatistiksel anlamlı azalma olmasına rağmen, iki grup arasında istatistiksel bir fark bulunamadı $(\mathrm{p}=0,387)$. $10 \mathrm{fr} \times 3 \mathrm{~Gy}$ 'lik doz-fraksiyon şemasında osteolitik alanlarda BMD'de ortalama \%23,4'lük istatistiksel olarak anlamlı bir artış görülürken $(\mathrm{p}<0,0001), 5$ fr $\times 4$ Gy'lik doz-fraksiyon şemasında da BMD'de ortalama \%19,9'lik anlamlı bir artış tespit edildi $(\mathrm{p}<0,0001)$. İki farklı doz-fraksiyon şeması arasında tedavi cevabı yönünden BMD'de istatistiksel olarak anlamlı bir fark bulunamamıştır $(\mathrm{p}>0,605)$.

TARTIŞMA ve SONUÇ: Osteolitik kemik metastazlarında iki farkl $10 \mathrm{fr} \times 3$ Gy ve $5 \mathrm{fr} \times 4$ Gy'lik doz-fraksiyon şeması sonrası ağrı cevabı ve BMD yönünden birbirine üstünlükleri bulunmamıştır. Kemik mineral dansitometre ölçümleri, radyoterapi tedavi cevabını bölgesel olarak daha hassas ve objektif olarak gösterebilmektedir.

Anahtar Kelimeler: Kemik mineral dansitometre, kemik metastazı, palyatif radyoterapi, fraksiyon, ağrı

\begin{abstract}
INTRODUCTION: Thirty - four patients with osteolytic bone metastasis were included in the study to evaluate bone mineral density and pain response in terms of treatment response after two different $10 \mathrm{fr} \times 3 \mathrm{~Gy}$ and $5 \mathrm{fr} \times 4$ Gy dose-fraction schemes.

METHODS: 18 of the patients have taken $10 \mathrm{fr} \times 3$ Gy and 16 of them have taken $5 \mathrm{fr} \times 4$ Gy radiotherapy treatment. Having taken the patient's self evaluation as basis in the pain tratment efficiency; the pain intensity is evaluated with respect to VAS pain scale from 1st day to 15 day daily, and finally at 45th day. BMD is measured with DXA (dual energy X-ray absorptiometry) two times; before treatment and after 6 months.

RESULTS: Even though there is a significant statistical decrease in the two different dose-fraction treatment with respect to time, no difference is found between the two groups ( $\mathrm{p}=0.387)$. It is evaluated that BMD has a $23.4 \%$ increase in the $10 \mathrm{fr} \times 3 \mathrm{~Gy}$ dose-fraction treatment group ( $<0.0001$ ); where it has a $19.9 \%$ increase in the $5 \mathrm{fr} \times 4$ Gy dose-fraction treatment group $(\mathrm{p}<0.0001)$. There is not a significant difference with respect to treatment response between the two dose-fraction treatment groups.

DISCUSSION and CONCLUSION: No predominance is found with respect to pain response and BMD between $10 \mathrm{fr} \times 3$ Gy and $5 \mathrm{fr} \times 4$ Gy dose-fraction treatment groups. Bone mineral density measurements locally indicates radiotherapy response more precisely.
\end{abstract}

Keywords: Bone mineral densitometry, bone metastases, palliative radiotherapy, fractionation, pain.

\section{GİRIŞ̧ ve AMAÇ}

Kemik metastazları akciğer ve karaciğerden sonra 3. s1kl1kta görülen metastatik yerleşim bölgesidir (1). Kanserli hastaların \%3-4'ünde tanı sırasında kemik metastazı olmakla birlikte bunların \%10-15'inde kemik metastazı ilk bulgudur ve kemik metastazı semptomlarıyla 
malignite tanıs1 konur. Son evreye gelmiş kanserli hastaların \%30-90'1nda kemik metastazı görülür $(2,3,4)$.

Malign kemik hastalığ 1 olan hastalarda güncel palyatif tedavi yaklaşımları arasında radyoterapi (RT), kemoterapi, hormon tedavisi, ortopedik cerrahi ve bifosfonatlar bulunmaktadır. Kemik metastazlı bazı olgularda beklenen yaşam süresi uzun olup analjezik ya da narkotik analjeziklerin uzun süre kullanımlarını yan etkileri nedeni ile sinırlamaktadır. Kemoterapi ya da hormon tedavisinin sağlayacağı palyasyon, bazı kanser türleri dışında kısa sürede elde edilemediği gibi, etkin ve uzun süreli olmadığı da bilinmektedir. Cerrahi ise, ağırlık taşıyan kemiklerin yoğun litik lezyonlarında patolojik fraktür gelişimini önlemek amacıyla ya da oluşmuş patolojik fraktürün fiksasyonu veya spinal kord basis1 olan hastaların acil tedavisinde radyoterapi ile birlikte kullanılan bir yöntemdir $(2,5,6)$.

Kemik metastazları kansere bağlı ağrının en sık nedenlerinden birisidir. Radyoterapi ağrı palyasyonunu kısa bir sürede sağlamaktadır ve bu palyasyon çoğu zaman uzun süreli olmaktadır, patolojik fraktür gelişmesini önlemesi ve minimal yan etki oluşturmas1 nedeni ile kemik metastazlarında ilk tercih edilen palyasyon yöntemlerindendir $(2,7,9,10)$.

Kemikte radyoterapi sonrası kanser hücrelerinde dejenerasyon ve nekroz oluşur. Daha sonra gelişen proliferatif fibröz doku bu hücrelerin yerini alır. Kaybolmuş fibröz stromada kollajen fibrilleri toplanır ve kan akımı artar. $\mathrm{Bu}$ yumuşak kollajen fibriller yumağı zamanla kalsifiye, mineralize olur. Osteoblastik aktivite kemik trabekülasyonunu çoğaltır. Sonuçta ağsı yapının yerini lameller kemik dokusu alır. Radyoterapinin tamamlanmasindan 3-4 hafta sonra rekalsifikasyonun radyolojik bulguları görülür. Normal kemik yapıs1 remodelizasyon 6 ay sonra gelişebilir $(9,10,11)$. Radyoterapi ile tümör büyümesi engellenirken rekalsifikasyon, remineralizasyon ve ağrı palyasyonu da sağlanmış olur. Radyoterapi sonrası yanıt değerlendirmesinde radyolojik değerlendirme ağrıya göre objektif bir yöntemdir.

Kemik metastazlarında farklı fraksiyon şemalarında, palyatif radyoterapi uygulamalarıyla ilgili prospektif-randomize, çalışmalar sonucunda ağrı palyasyonu, radyolojik cevap ve akut yan etkiler yönünden benzer sonuçlar elde edilmiştir $(2,8,9,11)$. Radyoterapi sonrasi kemik metastazlarının remineralizasyonunun değerlendiren az sayıda çalışma vardır. Kemik metastazlarının radyoterapiye cevabının değerlendirilmesinde genellikle ağrı skalaları kullanılmaktadır. Aslında bu yöntemler sübjektiftir ve hastanın ve doktorun içinde bulunduğu psikolojiden ve etrafindaki olaylardan kolayca etkilenerek sonuçları da olumlu ya da olumsuz etkileyebilmesi muhtemeldir. $\mathrm{Bu}$ nedenlerden dolayı kemik metastazlarının tedaviye cevabının değerlendirilmesi için objektif kriterlere ihtiyaç duyulmaktadır.

Çalışmamızda amacımız kemik metastazlarında değişik doz-fraksiyon şemalarına göre radyoterapi öncesi ve sonrası takiplerde metastatik odakların remineralizasyonunun Kemik Mineral Dansitometre (KMD) ölçümü ile elde edilecek sonuçların bir farklılık oluşturup oluşturmayacağının saptanması hedeflenmiştir. İlaveten ağrı palyasyonu ve performans değerlendirmesi de yapılmıştır. Bu amaçla $10 \mathrm{fr} \times 3$ Gy ve $5 \mathrm{fr} \times 4$ Gy olacak şekilde 2 değişik doz-fraksiyon şeması uygulandı. Gruplar arası sonuçlar kendi içlerinde ve literatürlerle karşıllaştııılarak radyoterapi sonrası cevabın objektif ve sübjektif değerlendirilmesi hedeflendi.

\section{YÖNTEM ve GEREÇLER}

Gazi Üniversitesi Gazi Hastanesi Radyasyon Onkolojisi Anabilim Dalı'na başvuran 34 osteolitik kemik metastazılı olguya tabakalandirma yapılmadan $5 \mathrm{fr} \times 4$ Gy ve $10 \mathrm{fr} \times 3$ Gy olacak şekilde 2 değişik dozfraksiyon şemasına gruplanarak palyatif radyoterapi programına alınmıştır. Çalışmamız G.Ü.T.F etik kurulundan onaylanmıştır. Olguların tümüne çalışmanın amacı hakkında bilgi verildi ve gerekli izinleri alınd.

Çalışmaya 18 yaş ve üzeri olan hatalardan, histolojik olarak primer malignitesi kanıtlanmış, tek ya da multipl osteolitik kemik metastazılı, Karnofsky 50 100 aralığında ve yaşam beklentisi 6 aydan fazla olan hastalardan yazılı bilgilendirilmiş olurları alınanlar dahil edildiler.

Olgulardan aynı bölgeye radyoterapi almış olanlar, 2 haftadan kısa süre önce geçirilmiş büyük cerrahi operasyon, travma ve derin biyopsi öyküsü, kontrolsüz hipertansiyon 
varlığ 1 , kronik karaciğer ve böbrek hastalığının olduğu durumlar ve hastanın çalışmayı sürdürmesine engel olacak sosyal ya da psikolojik bozukluğun olanlar çalışma dişı tutuldular.

Çalışmaya alınan olgulara radyoterapi öncesi demografik verileri, ağrının değerlendirilmesi (VAS skalası), rutin biyokimyasal testler ile RT öncesi ve RT sonrası 6. ay KMD (Kemik Mineral Dansitometre) ile lezyon bölgesi (RT tedavi alanı) değerlendirildi.

Çalışmada kullanılan 2 farklı doz fraksiyon şeması ( $5 \mathrm{fr} \times 4$ Gy - $10 \mathrm{fr} \times 3 \mathrm{~Gy}$ ), KMD ölçümü, ağrı yanıtı ve hastaların performans1 yönünden karşılaştırılarak değerlendirilmiştir.

VAS skalas1 hasta tarafindan radyoterapinin birinci gününden itibaren 15 . güne kadar günlük olarak her gün aynı saatte ve son olarak da 45. gün olmak üzere değerlendirilerek forma kaydedildi.

Tüm hastalara ya RT ile birlikte ya da öncesinde Bifosfonat başlanmıştı. RT sonrası takipte de bifosfonat kesilmeden kullanıma devam edildi. Bifosfonat başlanmayan ya da RT sonrası kullanımı kesilen hastalar çalışma dışı tutuldu.

Çalışmamızın verilerinin istatistiksel analizinde SPSS 13.0 programı kullanıldı. Çalışma verileri değerlendirilirken tanımlayıcı istatistiksel metodların yanı sira niceliksel verilerin karşılaştırılmasında ölçümlerimiz normal dağılım şartlarını sağlamadığından dolayı iki grup arasındaki değerlendirmeler Mann Whiyney $U$ test ile; ikiden fazla tekrarlayan ölçüm karşılaştırmaları Friedman Test ile bunun post hoc karşılaştırmaları ise Wilcoxon eşleştirilmiş iki örnek testi ile yapılmıştır. Niteliksel verilerin karşılaştırılmasında ise Ki-Kare testi ve Fisher Exact Ki-Kare testi kullanıldı. Sonuçlar \% 95'lik güven aralığında, anlamlılık $\mathrm{p}<0.05$ düzeyinde değerlendirildi.

\section{BULGULAR}

Histopatolojik olarak malignensi tanısı olup kemik metastazı olan 34 hastaya $10 \mathrm{fr} \times 3$ Gy ve $5 \mathrm{fr} \times 4$ Gy olacak şekilde 2 değişik dozfraksiyon şemas1 uyguland. Gruplar aras1 tabakalama yapılmadi. Birinci grupta kemik metastazlı 18 hastaya 10fr× 3Gy RT uyguland. İkinci grupta ise 16 kemik metastazlı hastaya 5 fr $\times 4$ Gy RT uyguland.

Gruplar arasi tabakalanma

yapılmamasına rağmen yaş, cinsiyet, kontrol süreleri, primer tümör tipi, kemik metastazı dışında başka organ metastazı varlığı, RT alanı dışında kemik metastaz odağı olup olmaması, Bifosfonat tedavisindeki değişiklikler, Kemoterapi, Hormonoterapi, ECOG-PS, ağrı VAS skalası ve KMD ölçümleri yönünden gruplar arsında karşılaştırma yapıldığında KiKare ve Fisher Exact Ki-Kare testi ile fark yoktu (p>0,05). Tablo-1'de RT öncesi grup özellikleri verilmiştir.

Tüm olguların RT tedavi alanı içerisine giren litik ve normal kemik alanlarının KMD ile $\mathrm{g} / \mathrm{cm}^{2}$ cinsinden değerleri ölçüldü. Radyoterapiden ortalama 6 ay sonra ayn alanlardan ve aynı ölçüm bölgelerinden litik ve normal kemiklerin KMD değerleri tekrar ölçüldü. Tüm grupta RT başlangıcı ölçülen litik alanların ve normal alanların KMD değerleri karşılaştırıldığında istatistiksel anlamlı bir fark bulunamadı $(\mathrm{p}>0,5)$. Ancak 6 . ayda ölçülen litik ve normal alanların KMD değerleri karşılaştırıldığında istatistiksel olarak litik alanlar lehine anlamlı bir artış bulunmuştur $(p<0,0001)$. RT alanı içinde kalan litik kemiklerin yine aynı alan içinde kalan normal kemiklere göre 6 . ayda KMD ölçümlerinde artış tespit edildi (Tablo 2) .

RT başı ve 6. ay litik alanların KMD ölçümleri karşılaştırıldığında istatistiksel olarak 6. ay ölçümleri lehine anlamlı bir artış bulunmuştur $(p<0,0001)$. Normal kemik alanlarının RT tedavi alanı içinde kalan RT baş1 ve 6. ay KMD ölçüm değerleri arasında istatistiksel anlamlı fark saptanmamıștır ( $p>0,05, \% 95$ 'li C.I çakıştığından dolayı anlaml kabul edilmedi (Tablo 3).

Grup I ve Grup II'nin RT başı litik alanların KMD ölçümleri karşılaştırıldığında istatistiksel açıdan anlamlı fark saptanmamıştır ( $p>0$,297). Grup I ve Grup II'nin RT sonras1 6 . ay KMD ölçümleri karşılaştırıldığında istatistiksel açıdan yine anlamlı fark saptanmamıştır $(p>0,825)$. Grup I ve Grup II tedavi protokolleri ile radyoterapi sonrası litik kemik dokusunda KMD ölçümlerinde kemik dansitesinde anlamlı artış görülmesine rağmen iki grup arasında cevap yönünden istatistiksel fark bulunamamıștır.

Litik tedavi alanlarının KMD ölçümlerinde, Grup I'de RT başına göre 6. ay 
KMD ölçümlerinde istatistiksel olarak anlamlı bir artış saptanmıştır $(\mathrm{P}<0,0001)$. Yine Grup II'de de RT başina göre 6. ay KMD ölçümlerinde istatistiksel olarak anlamlı bir artış saptanmıştır $(\mathrm{P}<0,0001)$.

Tablo-3 de görüldüğü üzere bizim çalışmamızda litik kemik alanlarının RT öncesi ve 6 . ay $\mathrm{KMD}$ ölçümlerinde $10 \mathrm{fr} \times 3$ Gy ve $5 \mathrm{fr} \times 4$ Gy'lik iki tedavi protokolünde de KMD'de istatistiksel olarak anlamlı artış saptadik. Ancak bu iki tedavi protokolünün RT sonrası litik alanlardaki kemik dansitesindeki artış yönünden karşılaştırıldığında bir birine üstünlügü istatistiksel olarak saptanmamıştır.

Normal tedavi alanlarının 6 . ay ölçümlerinde KMD ortalama değişim oranları; İki grup arasında ortalama KMD artış1 yönünden fark bulunamadı $(\mathrm{p}>0,569)$. $)$. Dolayıs1 ile radyoterapi sonrası Grup I ve Grup II tedavi protokollerinin normal kemik dokusu KMD ölçümleri üzerine istatistiksel olarak katkısı bulunamamıştır (Tablo 4).

Radyoterapi ile litik kemik dokusunda tedavi sonrası kemik dansitesinde istatistiksel olarak anlamlı bir artış olmaktadır. Radyoterapi ile litik kemik dokusunda dansiteyi artmasına rağmen RT tedavi alanı içindeki normal kemik dokusunun dansitesinde istatistiksel olarak anlamlı bir artış sağlamamaktadır.

Çalışmamızın ikinci bölümünde ağrılı litik metastazı olan olguların; Grup I'de (10fr $\times 3$ Gy) 18 olgudan 17'sinin, Grup II'de (5fr $\times 4$ Gy) 16 olgudan 12 'sinin farklı dozfraksiyon şemasına cevabını VAS skalası yönünden değerlendirdik. Olgular gruplara ayrılmadan ağrı skalaları yönünden değerlendirildiğinde ağrıda zamanla istatistiksel anlamlı bir azalma bulunmuştur $(\mathrm{p}=0,0001)$. İlk altı gün ağrıda hızlı bir azalma görülmekte, bunu takip eden günlerde ağrıdaki azalma h1z kaybetmekle beraber 14. güne kadar istatistiksel olarak anlamlı azalma devam etmektedir. Ağrıdaki azalmanın 14. gün, 15. gün ve 45. gün ölçümlerinde devam etmediği ve sabit kaldığ 1 istatistiksel olarak tespit edilmiştir. Şekil-1'de tüm olguların günlere göre ağrıdaki değişim grafiği gösterilmiştir.

Grup I ve Grup II ağriya cevap yönünden karşılaştırıldığında aralarında cevap yönünden istatistiksel anlamlı bir sonuç bulunamamışıı $(p=0,387)$. Hasta sayımızın azlığ1 ve iki grup arasında istatistiksel anlamlılık olmamasına rağmen Grup I'de 6. günden sonra da 14. güne kadar ağrıda azalma eğilimi devam etmekte olduğu halde Grup II'de 6. günden sonra ağrida azalma stabil kalmaktadır (Şekil 2).

Grup I ve Grup II arası ağrı dindirme skalası ve memnuniyet skalası yönünden istatistiksel anlamlı bir fark bulunamamıştır $(\mathrm{P}>0,05)$. Hastaların performanslarını değerlendirmek için Karnofsky performans skalası (ECOG-PS) kullanıldı. Radyoterapinin başında (I), 1,5 ay sonra (II) ve 6. ayda (III) olmak üzere üç kez değerlendirildi. Tüm hastalar için Friedman testinde RT başı ECOGPS' değerleri ile II. ve III. Kontrol ECOG-PS değerleri arasında istatistiksel anlamlı bir artış bulunmuştur (p0,001). II. ECOG-PS değerleri ile III. ECOG-PS değerleri arasında istatistiksel anlamlık bulunamamıştır. Hastalarin performans 1 1,5 ay sonras 1 kontrollerinde artış göstermektedir, ancak 6 . ay kontrollerinde artış devam etmeyip stabil kaldığ1 gözlemlenmiştir (Şekil-5). İki tedavi grubu karşılaştırıldığında RT başı ve 6 . ay ECOG-PS değerleri aras1 istatistiksel anlam bulunamamıştır $(\mathrm{P}>0,05)$. İkinci (II) kontrol ECOG-PS değerleri karşılaştırıldığında Grup I lehine istatistiksel anlamlı bir artış gözlemlenmiştir ( $\mathrm{p}=0,043)$.

Tablo-1 RT öncesi grupların genel özellikleri

\begin{tabular}{|c|c|c|c|c|c|}
\hline $\begin{array}{c}\text { Parametrele } \\
\mathrm{r}\end{array}$ & $\begin{array}{l}\text { Tüm } \\
\text { Gruplar }\end{array}$ & $\begin{array}{c}\text { Grup I } \\
(10 \mathrm{fr} \times 3 \\
\text { Gy })\end{array}$ & $\mid \begin{array}{c}\text { Grup II } \\
(5 \mathrm{fr} \times 4 \mathrm{~Gy})\end{array}$ & $\mathrm{P}^{*}$ Değeri & \\
\hline Yaş & $\begin{array}{c}50,9 \pm 2 \\
(\% 95 \\
\text { C.I }=46,8- \\
55)\end{array}$ & $\begin{array}{c}47,9 \pm 2,8 \\
(\% 95 \\
\text { C. } I=42-54)\end{array}$ & $\begin{array}{c}50,9 \pm 2 \\
(\% 95 \\
\text { C.I }=46,8- \\
55)\end{array}$ & $>0,1$ & \\
\hline \multirow[t]{2}{*}{$50 \mathrm{Yaş}$} & Üstü & 17 & 8 & 9 & \multirow{2}{*}{$>0,089$} \\
\hline & Alt1 & 17 & 11 & 6 & \\
\hline \multirow[t]{2}{*}{ Cinsiyet } & Erkek & 7 & 4 & 3 & \multirow{2}{*}{$>1$} \\
\hline & Kadın & 27 & 14 & 13 & \\
\hline \multirow{3}{*}{$\begin{array}{l}\text { Primer } \\
\text { tümör } \\
\text { tipi }\end{array}$} & Meme & 28 & 14 & 14 & \multirow{3}{*}{$>0,4$} \\
\hline & Akciğger & 4 & 2 & 2 & \\
\hline & Mide & 2 & 2 & & \\
\hline \begin{tabular}{|l|} 
Kemik dışı \\
organ \\
metastazları \\
varlığ 1
\end{tabular} & 8 & 4 & 4 & $>0,4$ & \\
\hline $\begin{array}{l}\text { RT başında } \\
\text { ağrı varlığı }\end{array}$ & 25 & 14 & 11 & $>0,6$ & \\
\hline $\begin{array}{l}\text { RT alanı } \\
\text { dışında } \\
\text { kemik } \\
\text { metastazı } \\
\text { varlığı }\end{array}$ & 17 & 8 & 9 & $>0,5$ & \\
\hline Kemoterapi & 10 & 7 & 3 & $>0,198$ & \\
\hline $\begin{array}{l}\text { Hormonoter } \\
\text { api }\end{array}$ & 11 & 7 & 4 & $>0,388$ & \\
\hline $\begin{array}{l}\text { RT başı } \\
\text { ECOG-PS }\end{array}$ & $\begin{array}{c}84,5 \pm 1,3 \\
(\% 95 \\
\text { C.I }=81,7-\end{array}$ & $\begin{array}{l}85 \pm 1,2 \\
(\% 95 \text { C.I }= \\
82,4-87,6) \\
\end{array}$ & $\begin{array}{c}85 \pm 2,2 \\
(\% 95 \\
. I=46,8-55)\end{array}$ & $>0,73$ & \\
\hline
\end{tabular}




\begin{tabular}{|c|c|c|c|c|}
\hline & $87,3)$ & & & \\
\hline $\begin{array}{l}\text { RT baş1 } \\
\text { ağn1 VAS }\end{array}$ & $\begin{array}{c}3,5 \pm 0,5 \\
(\% 95 \\
. I=2,6-4,4) \\
\end{array}$ & $\begin{array}{c}3,81 \pm 0,6 \\
(\% 95 \\
. \mathrm{I}=2,6-3,8) \\
\end{array}$ & \begin{tabular}{|c|}
$3 \pm 0,7$ \\
$095 \mathrm{C} . \mathrm{I}=1,4$ \\
$4,6)$ \\
\end{tabular} & $>0,4$ \\
\hline $\begin{array}{l}\text { RT başı } \\
\text { Litik kemik } \\
\text { KMD } \\
\text { ölçümü }\end{array}$ & $\begin{array}{c}, 040 \mathrm{~g} / \mathrm{cm}^{2} \\
\pm 0,048 \\
(\% 95 \\
\text { C.I }=0,94- \\
1,13)\end{array}$ & $\begin{array}{c}, 997 \mathrm{~g} / \mathrm{cm}^{2} \\
\pm 0,052 \\
(\% 95 \\
\text { C.I }=0,888- \\
1,107)\end{array}$ & \begin{tabular}{|c|}
, $087 \mathrm{~g} / \mathrm{cm}^{2}$ \\
$\pm 0,86$ \\
$(\% 95$ \\
C.I $=0,905-$ \\
$1,269)$
\end{tabular} & $>0,29$ \\
\hline $\begin{array}{l}\text { RT baş1 } \\
\text { normal } \\
\text { kemik } \\
\text { KMD } \\
\text { öçümü }\end{array}$ & $\begin{array}{c}, 958 \mathrm{~g} / \mathrm{cm}^{2} \\
\pm 0,051 \\
(\% 95 \\
\text { C.I }=0,853- \\
1,063)\end{array}$ & $\begin{array}{c}, 986 \mathrm{~g} / \mathrm{cm}^{2} \\
\pm 0,068 \\
(\% 95 \\
\text { C.I }=0,843- \\
1,13)\end{array}$ & $\begin{array}{c}0,926 \\
\mathrm{~s} / \mathrm{cm}^{2} \pm 0,08 \\
(\% 95 \\
\text { C.I }=0,755- \\
1,098)\end{array}$ & $>0,77$ \\
\hline
\end{tabular}

$\mathrm{P}^{*}=$ Ki-Kare ve Fisher Exact Ki-Kare testi

Tablo-2. Tüm grubun ortalama KMD değerlerine göre dağglımı

\begin{tabular}{|c|c|c|c|}
\hline \multirow[b]{2}{*}{ RT alanları } & \multicolumn{2}{|c|}{ Tüm Grup KMD (n=34) } & \multirow{2}{*}{$\begin{array}{c}\text { P değeri } \\
\text { (Wilcoxon Signed } \\
\text { Ranks) }\end{array}$} \\
\hline & $\begin{array}{l}\text { RT Öncesi KMD } \\
\mathrm{g} / \mathrm{cm}^{2}\end{array}$ & $\begin{array}{l}\text { 6. Ay KMD } \\
\mathrm{g} / \mathrm{cm}^{2}\end{array}$ & \\
\hline $\begin{array}{l}\text { Litik kemik } \\
\text { alanları }\end{array}$ & $\begin{array}{c}1,040 \mathrm{~g} / \mathrm{cm}^{2} \pm 0 \\
48 \quad(\% 95 \\
\text { C.I }=0,94-1,13)\end{array}$ & \begin{tabular}{|c|}
$1,264 \mathrm{~g} / \mathrm{cm}^{2} \pm$ \\
$0,055 \quad(\% 95$ \\
C.I $=1,151-$ \\
$1,378)$ \\
\end{tabular} & $<0,0001$ \\
\hline $\begin{array}{l}\text { Normal } \\
\text { kemik } \\
\text { alanları }\end{array}$ & $\begin{array}{c}0,958 \mathrm{~g} / \mathrm{cm}^{2} \pm \\
0,051 \\
(\% 95 \mathrm{C} . \mathrm{I}=0,853- \\
1,063)\end{array}$ & $\begin{array}{c}0,980 \mathrm{~g} / \mathrm{cm}^{2} \pm \\
0,051 \\
(\% 95 \\
\text { C.I }=0,876- \\
1,080)\end{array}$ & $>0,05^{*}$ \\
\hline $\begin{array}{l}\text { P değeri } \\
\text { (Mann- } \\
\text { Whitney U) }\end{array}$ & $>0,5$ & $<0,01$ & \\
\hline
\end{tabular}

* $\mathrm{P}=0,041$ olasına rağmen iki ölçümün \% 95'lik C.I aralığı çakışmaktadır bu nedenle p değeri anlamsız kabul edildi.

Tablo-3 Litik kemik alanlarının RT başı ve 6. ay KMD ölçümleri dağılım

\begin{tabular}{|c|c|c|c|}
\hline Ölçümler & $\begin{array}{c}\text { Grup I } \\
(10 \mathrm{fr} \times 3 \mathrm{~Gy})\end{array}$ & $\underset{(5 \mathrm{fr} \times 4 \text { Gy })}{\text { Grup II }}$ & $\begin{array}{c}\text { P Değeri } \\
\text { (Mann- } \\
\text { Whitney U) }\end{array}$ \\
\hline $\begin{array}{l}\text { RT Başı } \\
\text { KMD } \\
\text { ölçümü }\end{array}$ & $\begin{array}{c}0,997 \mathrm{~g} / \mathrm{cm}^{2} \pm \\
0,052 \\
\\
(\% 95 \text { C.I }=0,880- \\
1,100)\end{array}$ & $\begin{array}{c}1,087 \mathrm{~g} / \mathrm{cm}^{2} \pm \\
0,086 \\
(\% 95 \text { C.I }=0,905- \\
1,269)\end{array}$ & $>0,297$ \\
\hline $\begin{array}{l}\text { 6. Ay KMD } \\
\text { ölçümü }\end{array}$ & $\begin{array}{c}1,230 \mathrm{~g} / \mathrm{cm}^{2} \pm \\
0,051 \\
\\
(\% 95 \text { C.I }=1,120- \\
1,339)\end{array}$ & $\begin{array}{c}1,303 \mathrm{~g} / \mathrm{cm}^{2} \pm \\
0,105 \\
\\
(\% 95 \text { C.I }=1,080- \\
1,527)\end{array}$ & $>0,825$ \\
\hline $\begin{array}{l}\text { P Değeri } \\
\text { (Wilcoxon } \\
\text { Signed } \\
\text { Ranks) }\end{array}$ & $<0,0001$ & $<0,0001$ & \\
\hline
\end{tabular}

Tablo-4. Normal kemik alanlarının RT başı ve 6. ay KMD ölçümleri dağ 11 mı

\begin{tabular}{|l|c|c|c|}
\hline Ölçümler & $\begin{array}{c}\text { Grup I } \\
\mathbf{( 3 \times 1 0 G y )}\end{array}$ & $\begin{array}{c}\text { Grup II } \\
\mathbf{( 4 \times 5 G y )}\end{array}$ & $\begin{array}{c}\text { P Değeri } \\
(\text { Mann-Whitney } \\
\text { U) }\end{array}$ \\
\hline RT Başı KMD & $0,986 \mathrm{~g} / \mathrm{cm}^{2}$ & $0,926 \mathrm{~g} / \mathrm{cm}^{2} \pm$ & $>0,772$ \\
\hline
\end{tabular}

\begin{tabular}{|c|c|c|c|}
\hline ölçümü & \begin{tabular}{|c|} 
$\pm 0,068$ \\
$(\% 95$ \\
C.I $=0,843-$ \\
$1,130)$ \\
\end{tabular} & $\begin{array}{c}0,086(\% 95 \\
\text { C.I }=0,755-1,098)\end{array}$ & \\
\hline $\begin{array}{l}\text { 6. Ay KMD } \\
\text { ölçümü }\end{array}$ & \begin{tabular}{|c|}
$0,996 \mathrm{~g} / \mathrm{cm}^{2}$ \\
$\pm 0,065$ \\
$(\% 95$ \\
C.I $=0,860-$ \\
$1,132)$ \\
\end{tabular} & $\begin{array}{c}0,962 \mathrm{~g} / \mathrm{cm}^{2} \pm \\
0,083(\% 95 \\
\text { C.I }=0,786-1,138)\end{array}$ & $>0,959$ \\
\hline \begin{tabular}{|l|} 
P Değeri \\
(Wilcoxon \\
Signed Ranks)
\end{tabular} & $>0,381$ & $>0,05^{*}$ & \\
\hline
\end{tabular}

$\mathrm{P}=0,041$ olasına rağmen iki ölçümün \% 95'lik C.I aralığ 1 çakışmaktadır bu nedenle $\mathrm{p}$ değeri anlamsız kabul edildi.

Şekil-1 Tüm olguların günlere göre ağrı değişim yüzdesi grafiği

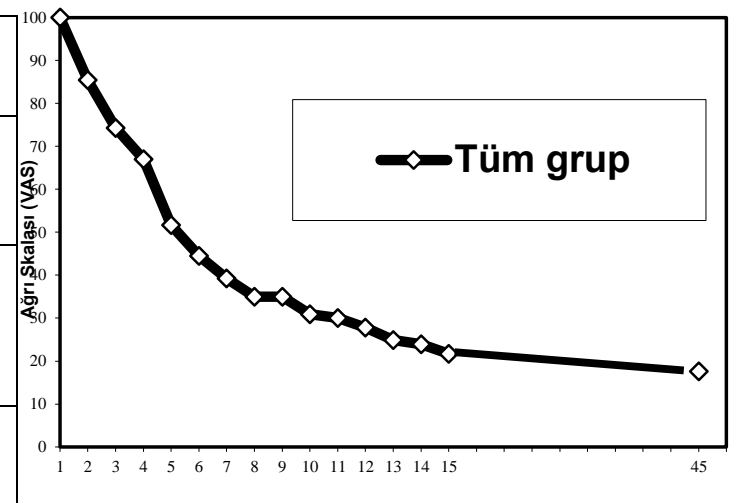

Şekil-2 Grup I ve II'de günlere göre ağrının yüzde değişim grafiği

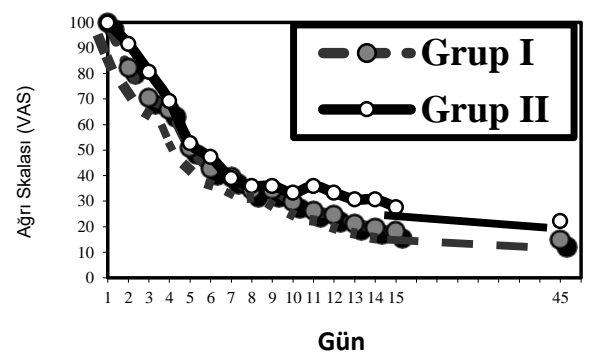

Şekil-3 Hastaların ECOG PS değerlerini gruplara göre değişim grafiği

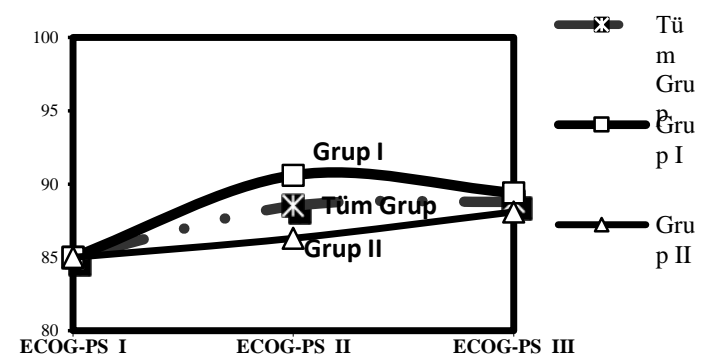

Adress for correspondence: Uzm. Dr. Fatih Göksel Ehmet Akif Ersoy Mah. Vatan Cad. No: 91 Yenimahalle /ankaraposta Kodu: 06200 Ankara - Türkiye e-mail: fatihgoksel@gmail.com

Available at www.actaoncologicaturcica.com

opyright $\mathbb{C}$ Ankara Onkoloji Hastanesi 


\section{TARTIȘMA}

Kemik metastazlarının \%80'ini meme ve prostat kanserleri oluşturur $(1,2,8)$. Çalışmamızda ise tüm olguların primer tümör tipine göre dağ 11 lım1; \%82,4 Meme Ca, \%11,8 Akciğer $\mathrm{Ca}$ ve \%5,9'da Mide Ca'dır. Çalışmada prostat $\mathrm{Ca}^{\prime}{ }^{\prime}$ ı olguların olmayışı bu olguların metastazlarının s1klıkla sklerotik nitelikte olmasından dolayıdır. Osteolitik kemik metastazlarının primer tümör tipine göre dağılımı olgu sayımız az da olsa çalışmamızda literatürle benzer oranlardadır.

Radyoterapinin analjezik etkisinin mekanizması tam olarak bilinmemektedir (12). Ağrı palyasyonu nedeni; tümörde küçülme, kemik hücrelerinin etkilenerek kimyasal ağrı mediatörleri salgılaması, erken dönemde inflamasyonun azalması ya da geç dönemde radyoterapiye sekonder kalsifikasyon ve ossifikasyon gelişmesi olabilir $(13,14)$. Palyatif radyoterapi protokollerine ilişkin değişik dozfraksiyon şemaları kullanılarak yapılan çok sayıda randomize çalışmanın sonuçlarında halen görüş birliğine varılamamıştır. Optimal doz ve fraksiyon şemaları çok değişken olmakla beraber, ağn palyasyonları arasında belirgin bir fark bulunamamıştır $(1,2,4,8,15$ 20). Uzun süreli, maliyeti yüksek ve hastanın kliniğe bağlı kaldı̆̆ süreyi uzatan palyatif şemaların, kısa süreli şemalarla elde edilen palyasyon oranlarına üstünlügünü gösteren çalışmaların yanı sıra fark olmadığını bildiren randomize çalışmalarında olması bu alanda fikir birliği oluşmadığını göstermektedir.

RTOG 74-02 çalışmasında Tong ve ark. soliter kemik metastazlarına 40 Gy/ 15 fraksiyon ve $20 \mathrm{~Gy} / 5$ fraksiyondan oluşan iki fraksiyon şemas1, multiple kemik metastazlarına da $15 \mathrm{~Gy} / 5$ fraksiyon, $20 \mathrm{~Gy} / 5$ fraksiyon, $25 \mathrm{~Gy} / 5$ fraksiyon ve $30 \mathrm{~Gy} / 10$ fraksiyon olacak şekilde 4 ayrı fraksiyon şeması uygulamışlar. $\mathrm{Bu}$ çalışmada 1016 hastadan 266's1 soliter kemik metastazı, 750'si ise multipl kemik metastazlı olgu farklı dozfraksiyon şemalı tedavi protokollerine alınmış. Yapılan istatistiksel analiz sonucunda tedavi yanıtı, ağnı yönünden hem soliter kemik metastazlı grupta hem de multipl kemik metastazlı grupta düşük doz ve fraksiyon sayısının, yüksek doz ve fraksiyon sayısı kadar etkili olduğunu bulmuşlardır. Soliter metastazlarda $5 \mathrm{fr} \times 400 \quad$ cGy'lik tedavi şemasında $15 \mathrm{fr} \times 270 \mathrm{cGy}$ tedavi şemasına göre patolojik kırık gelişimine daha sık rastlanıldığı gösterilmiş. İki grup arasında tedavi süresi ve cevab1 yönünden anlamlı bir fark bulunamadığı bildirmişlerdir. (14).

Blitzer; RTOG 74-02 çalışmasında Tong ve arkadaşlarının yaptığı ve sonucunda tedavi yanıtı ile fraksiyon arasında anlamlı bir ilişki bulunmayan çalışmayı tekrar analiz etmiştir. Blitzer, Tong ve arkadaşlarının çalışmasında kullandıkları verileri farklı teknikler ve istatistik metotlarla yeniden değerlendirdiğinde; yüksek doz ve uzatılmış protokollerin $(10 \mathrm{fr} \times 270 \mathrm{cGy}$ ve $10 \mathrm{fr} \times 300 \mathrm{cGy})$ kısa süreli tedavilere göre istatistiksel olarak daha iyi cevap verdiğini ve diğer k1sa süreli tedavi protokollerinin $(5 \mathrm{fr} \times 300 \mathrm{cGy}, 4 \mathrm{fr} \times 400$ cGy ve $5 \mathrm{fr} \times 500$ cGy) kendi aralarında karşılaştırdığında cevap yönünden istatistiksel anlamlı bir fark bulunamadığını bildirmiştir. İkinci değerlendirmede fraksiyon sayısının artışının anlamlı katkısı vurgulanmıştır. Soliter metastazlarda $5 \mathrm{fr} \times 400 \quad$ cGy'lik tedavi şemasında $15 \mathrm{fr} \times 270 \mathrm{cGy}$ tedavi şemasına göre patolojik kırık gelişimine daha sık rastlanıldığ 1 gösterilmiştir $(14,23)$.

Ben-Josef ve ark. yaptıkları bir metaanalizde 1723 olguyu içeren 5 retrospektif çalışmayı tam ağrı palyasyonu ile biyolojik efektif doz (BED) arasındaki ilişki yönünden incelemişlerdir (21). Araştırmada 4 Gy(BED=5,6 Gy), 8Gy (BED=14,4 Gy), $5 \mathrm{fr} \times 4$ Gy $(\mathrm{BED}=28 \mathrm{~Gy}), 10 \mathrm{fr} \times 3$ Gy $(\mathrm{BED}=39 \mathrm{~Gy})$ ve $15 \mathrm{fr} \times 2,7$ Gy $(\mathrm{BED}=51,4 \mathrm{~Gy})$ gibi farklı doz ve fraksiyon şemaları karşılaştırılmış. Sonuç olarak biyolojik efektif doz arttıkça tam ağrı yanıtının arttığını saptamışlardır. Bu artış ilk 4 haftada anlamlı bulunmamış ancak 4-6 ayda geç tam yanıtı BED ile ilişkili bulmuşlardır (48). Bizim çalışmamızda ise $5 \mathrm{fr} \times 4$ Gy $(\mathrm{BED}=28 \mathrm{~Gy})$ ve $10 \mathrm{fr} \times 3 \mathrm{~Gy}(\mathrm{BED}=39 \mathrm{~Gy})$ iki doz-fraksiyon şeması arasında biyolojik efektif doz (BED) ağrı palyasyonu yönünden istatistiksel anlamlı fark bulunmamıştır ( $\mathrm{P}>$ $0,05)$.

$\mathrm{Wu}$ ve ark. 16 prospektif randomize çalışmayı; ağrı palyasyonu, ağrısız geçen süre, akut yan etkiler, tekrar 1şınlama gereksinimi, patolojik fraktür gelişimi açısından değerlendirmişlerdir. Analizler yapılırken kategoriler tek fraksiyonda farklı dozlar, multipl fraksiyonda farklı dozların yanı sıra tek ve multipl fraksiyonlarin birbiriyle karşılaştırılmasını yapmışlardır (22). Sonuçta, tek ya da multiple fraksiyon uygulanmasinın 
ve tek fraksiyonda 4 ya da 8 Gy uygulanmasının ağrı yanıtında istatistiksel bir fark oluşturmadığını bildirmiş̧lerdir. Ortalama ağrısız geçen süre 11-12 hafta olup, tek ya da multipl fraksiyon arasinda fark bulamamışlardır. Radyobiyolojik eşdeğer doz BED cinsinden 35Gy'nin üstünde ise ağrısız geçen süre anlamlı olarak uzun bulunurken, tekrar radyoterapi uygulanım gereksinimi radyobiyolojik olarak düşük dozlarda arttığını saptanmışlardır. Benzer şekilde patolojik fraktür gelişiminin fraksiyon sayısı ve doz azaldıkça arttığını tespit etmişlerdir (22).

Bizim çalışmamızda, ağrılı kemik metastazları hangi tedavi modeli kullanılmış olursa olsun ( $10 \mathrm{fr} \times 3$ Gy ve $5 \mathrm{fr} \times 4 \mathrm{~Gy})$ tedaviye cevap esas olarak subjektif bir gösterge olan ağr1 palyasyonu (VAS skalası) ve yaşam kalitesi yönünden (ECOG-PS) ele alınmış, hastalardan alınan bilgilere göre değerlendirilmiştir. Tüm olgular ağrı skalası yönünden değerlendirildiğinde, ağrıda zamanla istatistiksel anlamlı bir azalma olduğu bulundu ( $\mathrm{p}=0,001$ ). İlk 6 gün ağrıda hızlı bir azalma görülmekle birlikte bunu takip eden günlerde ağrıdaki azalma, hız kaybetmekle beraber devam etmekte idi. 14. günden sonra 45 . güne kadar geçen süre içerisinde ağrının azalmayıp sabit kaldığını tespit edilmiştir ( $p>0,005)$.

Gruplar bazında karşılaştırma yapıldığında, $10 \mathrm{fr} \times 3$ Gy ve 5 fr $\times 4$ Gy fraksiyon şemaları arasında ağrının azalması yönünde iki tedavi protokolü arasında anlamlı bir fark bulunamamıştır $(p=0,387$ ). Hasta sayımızın azlığı ve iki grup arasında istatiksel anlamlı bir fark olmamasına rağmen, $10 \mathrm{fr} \times 3$ Gy'lik tedavi protokolünde 2. günden (RT başladıktan bir gün sonra) 14. güne kadarki süre içerisinde ağrıda anlamlı azalma devam ederken, $5 \mathrm{fr} \times 4$ Gy'lik tedavi protokolünde 2. günden (RT başladıktan bir gün sonra) itibaren ağrıda azalma başlayarak 7. güne kadar devam etmiş, daha sonra stabil kaldığ gözlemlenmiştir.

Radyoterapi başlangıcına göre performans ( ECOG-PS ) yönünden iki tedavi grubu arasında karşılaştırma yapıldığında, 1,5 ay sonraki kontrollerde $10 \mathrm{fr} \times 3$ Gy'lik tedavi kolunda $5 \mathrm{fr} \times 4$ Gy'lik tedavi koluna göre ECOG-PS'de artış yönünde istatiksel olarak anlamlı bir fark bulunmasına $(p=0,043)$ karşın, 6.ayda yapilan kontrollerde anlamlı bir fark bulunamamışırı $(\mathrm{p}>0,05)$. $5 \mathrm{fr} \times 4$ Gy'lik tedavi kolunda radyoterapi başına göre 1,5 ve 6 ay ECOG-PS değerleri arasında anlamlı fark bulunmamıştır $(\mathrm{p}=0,101) .10 \mathrm{fr} \times 3$ Gy'lik tedavi kolunda ise radyoterapi başına göre 1,5 ve 6 ay ECOG-PS değerleri arasında artış yönünde anlamlı bir fark bulunmasına $(\mathrm{p}=0,001)$ karşın, 1,5 ay ve 6 . ay arasinda performansin stabil kaldığı gözlemlenmiştir $(\mathrm{P}=0,705)$.

Gruplar arasında ağr1 dindirme skalası ve memnuniyet skalası yönünden istatistiksel anlamlı bir fark bulunamamıştır ( $p>0,05)$.

Lokalize radyoterapide en uygun fraksiyon dozu ve total doz konusunda yapilan çalışmalarda görüş birliğine varılamamıştır. Bununla birlikte prospektif randomize tek ve çok merkezli çok sayıda araştırmada fraksiyon sayısının etkisi de bulunamamıştır. Bizim çalışmamızda da iki farklı doz-fraksiyon şeması arasında ağrı cevabı ve performans durumu açısından literatürle ile uyumlu sonuçlar gözlemlenmiştir.

Kemik metastazlarında radyoterapi sonras1 objektif cevap değerlendirmesinde daha çok radyolojik yöntemlerle kemik yapımyıkım markerleri kullanılmaktadır $(11,24)$. Osteolitik metastazlarda lokal radyoterapi sahalarında, radyolojik görüntüleme yöntemleri ile RT sonrasında sklerozda artış, lezyon sayısı ve büyüklüğünde azalma görülmesi objektif cevap göstergeleri olarak kabul edilmektedir. Radyoterapinin farklı dozfraksiyon şemalarının etkinliğini subjektif olarak değerlendiren yöntemler arasında kemik dansite ölçümleri diğer yöntemlere göre daha objektif bulgular vermekle beraber bu yönde literatürde sınırlı sayıda çalışma vardır.

Shapiro ve ark. 9 meme kanserli kemik metastazlı hastaların tedaviye cevaplarını DXA (dual-energy x-ray absorptiometry) cihazı ile objektif değişiklerin gösterilebilineceğini araştırmışlardır. Hastaların tedavi öncesi, 2.ay ve 6. ayda; DXA cihazı, CT, direkt grafi ve kemik sintigrafisi ile tedavi cevaplarını değerlendirmişlerdir. Sistemik tedavi sonras1 KMD'de 0-2. ay aras1 \%10.7, 2-6.ay arasinda $\% 5$ ve $0-6$. ayda \% 16.7 oranında değişiklikler bulmuşlardır. KMD'deki değişikliklerin 0-2 ve 0-6.aylarda daha belirgin olduğunu tespit etmişlerdir. KMD'deki bu değişiklikler direkt grafi ve CT' deki bulgularla uyumlu iken, kemik sintigrafisi ile daha az uyumlu bulunmuştur. Litik kemik metastazlı hastaların sistemik tedaviye cevaplarının takibinde DXA cihazının kullanılabileceğini ileri sürmüşlerdir (27). 
Koswig ve ark. kemik metastazlı 107 hastayı iki farklı doz-fraksiyon şeması (10fr $\times 3$ Gy, $1 \mathrm{fr} \times 8$ Gy) sonras1 remineralizasyon yönünden prospektif olarak incelemişler. $\mathrm{Bu}$ çalışmada remineralizasyon; RT baş1-bitimi, 6 hafta, 3. ay ve 6. ayda CT kullanilarak değerlendirilmiş. Altınc1 ay kontrollerindeki kemik dansitesinde $1 \mathrm{fr} \times 8$ Gy'de \%120'lik artış olurken, $10 \mathrm{fr} \times 3$ Gylik doz-fraksiyon şemasında ise ortalama \%173'lik istatistiksel olarak anlamlı bir artış bulmuşlardır. Osteolitik kemik metastazlarında RT sonrası ağrı cevabı ve remineralizasyon açısından $10 \mathrm{fr} \times 3$ Gy'lik doz-fraksiyon şemasının daha etkili olduğunu bildirmişlerdir (25).

Tanja ve ark palyatif radyoterapi ile tedavi edilen 1047 osteolitik olguyu farklı tedavi şemaları $(5 \mathrm{x} 4 \mathrm{~Gy}, 10 \mathrm{x} 3 \mathrm{~Gy}, 14 \times 2.5 \mathrm{~Gy}$ ve $20 \times 2 G y$ ) sonras1 yanit1 radyolojik olarak değerlendirdiklerinde anlamlı bir fark gözlemlememişlerdir (2).

Edward ve ark. meme $\mathrm{Ca}$ osteolitik kemik metastazl1, bifosfonat kullanan 25 olguya palyatif radyoterapi uygulamışlar; radyoterapi öncesi ve 3 . ayda osteolitik metastazları kemik dansitesindeki değişiklikler yönünden BT (Bigisayarlı Tomografi) ile değerlendirmişlerdir. Ortalama kemik dansitesindeki değişiklikler $1 \mathrm{fr} \times 8$ Gy'de 128 , $5 \mathrm{fr} \times 4$ Gy'de 141 ve $10 \mathrm{fr} \times 3$ Gy'de ise 145 gibi birbirine yakın oranlarda bulunmuştur. Radyoterapi sonrası kemik dansitesinde tedavi grupları arasinda anlamlı bir fark bulunamamasının nedenlerini; hasta sayısının azlığı, bifosfonat tedavisi ve son 2 aylık takip periyodu boyunca uygulanan sistemik tedaviye bağlamışlardır (26).

Yukarıdaki çalışmalarda da görüldüğü gibi bifosfanat tedavisi KMD üzerine olumlu etki yapmaktadır. Hormon tedavisi olarak; tamoksifen kullanımı postmenopozal hastalarda KMD üzerine koruyucu etki yapmakla beraber premenapozal hastalarda minimal bir azaltıcı etki yapmaktadır. Goserelin kullanımında da KMD'de azalma olmaktadır. Kemoterapi de kemik metastazlı olgularda kullanılan ajanlara bağlı olarak KMD'de artış yapabilmektedir. Bunların dışında kemik mineral dansite ölçümleri; ırk, cinsiyet, yaş, beslenme, fiziksel aktivite, ölçüm yapılan bölge ve kullanılan yönteme bağlı olarak değișebilmektedir $(27,28)$.

Bizim çalışmamızda olguların tümünde ya RT ile beraber ya da daha önceden bifosfonat kullanımına başlanmıştı. RT bittikten sonra 6. ay kontrollerine kadar olan dönemde de bifosfonat kullanılmaya devam edilmiştir.

KMD ölçümünde literatürde farkl1 cihazlar kullanılmıştır. Yine ölçüm tekniği olarak da farklı lokalizasyonlardan ölçüm yapılmıştır. Bizim çalışmamızda KMD ölçümünde hassas cihazlardan olan DXA (dual enerji X-ray absopsiyometri) kullanıldı. Ölçüm tekniği ve lokalizasyonu olarak da osteolitik kemik metastazını, sağlam kemik alanlarını da içerecek şekildeki RT tedavi volümü içerisinde kalan litik ve normal kemik bölgelerinden tedavi başında ve 6 . ayda aynı bölgeleri içerecek şekilde kutucuklara bölünerek KMD ölçümleri yapıldı. Böylece her ölçümde aynı alan ve aynı kutucuklar temel alınarak hata payı minimuma indirildi.

Takiplerimiz esnasında $10 \mathrm{fr} \times 3$ Gy'lik doz-fraksiyon şemasında osteolitik alanlarda KMD'de ortalama \%23,4'lük istatistiksel olarak anlamlı bir artış görülürken $(p<0,0001)$, $5 \mathrm{fr} \times 4$ Gy'lik doz-fraksiyon şemasında da KMD'de ortalama \%19,9'lik anlamlı bir artış tespit ettik $(p<0,0001)$.

Radyoterapi tedavi alanı içinde kalan normal kemik alanların KMD ölçüm değerlerinde ise; $10 \mathrm{fr} \times 3$ Gy'de $\% 0,9$ ve $5 \mathrm{fr} \times 4$ Gy'de \%3,8'lik istatistiksel olarak anlamlı olmayan artış bulunmuştur ( $\mathrm{p}>0,05)$.

Çalışmamızın sonucunda literatürle uyumlu olarak KMD'de artış tespit edilmiştir. $10 \mathrm{fr} \times 3$ Gy ve $5 \mathrm{fr} \times 4$ Gy iki farklı doz-fraksiyon şeması arasında tedavi cevabının KMD ile ölçümü yönünden istatistiksel olarak anlamlı bir fark bulunamamıştır ( $p>0,605)$.

Radyoterapi tedavi sahası içindeki osteolitik alanlar, normal alanlara göre RT'ye daha selektif cevap vermektedir. Bu sayede osteolitik alanlarda sağlam bölgelere göre kemik dansitesinde daha fazla artış olduğu görülmüştür.

Kemik mineral dansitometre ölçümleri radyoterapi tedavi cevabını bölgesel olarak daha hassas ve objektif olarak gösterebilmektedir.

\section{SONUC}

Eksternal radyoterapi, yüksek palyasyon oran1, k1sa süreli uygulanma imkanı, toksisitesi az ve tekrar uygulama imkanı olması nedeni ile 
kemik metastazlarının palyatif tedavisinde kullanılan en önemli tedavi modalitesi olmaya devam etmektedir.

Amacımız hastanın yaşam kalitesini ve performansını olumsuz yönde etkileyen ağrının giderilmesinin yanı sira, en uygun ve etkili tedavi cevabını elde edebileceğimiz dozfraksiyon şemasının belirlemekti. Kemik metastazlarında palyatif amaçlı kullanılan eksternal radyoterapinin bu güne kadar yapilan çalışmaların çoğunluğuyla uyumlu olarak, ağrı palyasyonu açısından $10 \mathrm{fr} \times 3$ Gy ve $5 \mathrm{fr} \times 4$ Gy'lik iki farklı doz fraksiyon şeması arasında anlamlı fark bulunmamıştır.

Çalışmamızda literatürle uyumlu olarak KMD'de artış tespit edilmiştir. $10 \mathrm{fr} \times 3$ Gy ve 5 fr $\times 4$ Gy'lik iki farklı doz-fraksiyon şeması arasında tedavi cevabının KMD ile ölçümü yönünden istatistiksel olarak anlamlı bir fark bulunamamıştır. Radyoterapi tedavi sahası içindeki osteolitik alanlar normal alanlara göre RT'ye daha selektif cevap vermektedir. Bu sayede osteolitik alanlarda sağlam bölgelere göre kemik dansitesinde daha fazla artış olduğu görülmüştür. Kemik mineral dansitometre ölçümleri, radyoterapi tedavi cevabını bölgesel olarak daha hassas ve objektif olarak gösterebilmektedir.

Yukarıdaki sonuçlar 1şığında kemik metastazlı hastalara palyatif radyoterapi dozfraksiyon şeması seçiminde çalışmamız ve literatürlere göre karar verirken; hastaya ait özellikler, tedavi etkileşimleri, fiziki şartlar, iş yükü ve ekonomik maliyetler göz önünde bulundurulmalıdır.

\section{REFERENCES}

1. Li Z, Zhixin G. Clinical Characteristics and Prognostic Factors in Bone Metastases from Lung Cancer.Med Sci Monit. 2017; 23: 40874094. x1x

2. Sprave T, Hees K, Bruckner, $T$ et al . The influence of fractionated radiotherapy on the stability of spinal bone metastases: a retrospective analysis from 1047 cases, Radiat Oncol. 2018; 13: 134. x2x

3. Rougraff BT. Evaluation of the patient with carcinoma of unknown origin metastatic to bone. Clin Orthop. 415 (Supl) :S105-9, 2003.

4. Kong W, Zhang-Salomons J, Hanna TP, Mackillop WJ. A population-based study of the fractionation of palliative radiotherapy for bone metastasis in Ontario. Int $\mathrm{J}$ Radiat Oncol Biol Phys. 2007 Nov 15;69(4):1209-17.)
5. Payne R. Orthopedic surgical management of skeletal complications of malignancy. Cancer 80: 1614-27, 1997.

6. Lipton A, Theriault RL, Hortobágyi GN et al. Pamidronate prevents skeletal complications and is effective palliative treatment in women with breast carcinoma and osteolytic bone metastases: long term follow-up of two randomized, placebo-controlled trials. Cancer, 88:1082-1090, 2000.

7. Regine WF, Tibbs PA, Young A, et al. Metastatic spinal cord compression: A randomized trial of direct decompressive surgical resection plus radiotherapy vs. radiotherapy alone. Int $\mathrm{J}$ Radiat Oncol Biol Phys 57(Suppl. 2):S125, 2003

8. Steenland E, Leer JW, van Houwelingen H, et al.The effect of a single fraction compared to multiple fractions on painful bone metastases: a global analysis of the Dutch Bone Metastasis Study. Radiother Oncol 52(2):101-9. 1999.

9. Vassilis K, Zoi L, Anna Z, Kyriaki M ve John R. K. Bone Density as a Marker of Response to Radiotherapy in Bone Metastatic Lesions: A Review of the Published Data. Int J Mol Sci. 2016 Sep; 17(9): 1391

10. Lim FMY, Bobrowski A, Agarwal A, Silva MF. Use of corticosteroids for pain control in cancer patients with bone metastases: a comprehensive literature review. Curr Opin Support Palliat Care. 2017 Jun;11(2):78-87

11. Ranki Sheli: Bone Metastases diagnoses and treatment. Radiology 1.st edition (Ed: Rubens R.D and Folgeman I.). London , SpringerVerlang Lmt :63-82, 1991.

12. Vit JP, Ohara PT, Tien DA, el al, Jasmin L. The analgesic effect of low dose focal irradiation in a mouse model of bone cancer is associated with spinal changes in neuromediators of nociception. Pain. 2006 Jan;120(1-2):188-201

13. Francesca De F, Andrea $P$, Daniela M, and Vincenzo $\mathrm{T}$. The role of radiation therapy in bone metastases management. Oncotarget. 2017 Apr 11; 8(15): 25691-25699

14. Tong D, Gillick L, Hendrickson FR. The palliation of symptomatic osseous metastases: final results of the Study by the Radiation Therapy Oncology Group. Cancer. Sep 1;50(5):893-9, 1982

15. Shakespeare TP, Lu JJ, Back M, et al. Patients' preference for radiotherapy fractionation schedule in the palliation of painful bone metastases. J Clin Oncol 2003;21:2156-2162

16. Kachnic L, Berk L. Palliative single-fraction radiation therapy: How much more evidence is needed? J Natl Cancer Inst 2005; 97:786-788

17. 16) Nielsen OS, Bentzen SM, Sandberg E, Gadeberg CC, Timothy AR. Randomized trial of single dose versus fractionated palliative radiotherapy of bone metastases. Radiother Oncol.;47(3):233-40, 1998.

18. 17) Van der Linden YM, Kroon HM, Dijkstra SP, Lok JJ, Noordijk .Simple radiographic parameter predicts fracturing in metastatic femoral bone lesions: results from a 
randomised trial.; Dutch Bone Metastasis Study Group. Radiother Oncol, 69(1):21-31, 2003

19. Van der Linden YM, Steenland E, van Houwelingen HC, Post WJ, Oei B, Marijnen CA, Leer JW. Patients with a favourable prognosis are equally palliated with single and multiple fraction radiotherapy: Results on survival in the Dutch Bone Metastasis Study. Radiother Oncol, 78(3):245-53, 2006.

20. Haddad P, Wong RK, Pond GR, Soban F, Williams D, McLean M, Levin W, Bezjak A. Factors influencing the use of single vs multiple fractions of palliative radiotherapy for bone metastases: a 5-year review .Clin Oncol (R Coll Radiol),17(6):430-4, 2005

21. Ben-Josef E, Shamsa F, Youssef E, Porter AT. External beam radiotherapy for painful osseous metastases: pooled data dose response analysis Int J Radiat Oncol Biol Phys, 1;45(3):715-9, 1999.

22. Wu JSY, Wong R, Johnston M, Bezjak A, Whelan T.Meta-analysis of dose-fractionation radiotherapy trials for the palliation of painful bone metastases Int J Radiat Oncol Biol Phys, 55(3):594-605, 2003

23. Blitzer PH: Reanalysis of the RTOC study of the palliation of symptomatic osseous metastases. Cancer 55: 1468-72, 1985
24. Woitg HW, Pecherstorfer C, ve arkl. Novel serum markers of bone resorption: clinical assessment and comparison with established urinary indices. J Bone Miner Res, 14: 792801, 1999

25. Koswing S, Budach V. Remineralization and pain relief bone metastases after differrent radiotherapy fraction. Srahlenther Onkol 175: 500-8, 1999.

26. Chow E, Holden L, Rubenstein J,.Computed tomography (CT) evaluation of breast cancer patients with osteolytic bone metastases undergoing palliative radiotherapy--a feasibility study. Radiother Oncol, 70(3):291-4. 2004

27. Lunt M, Masaryk P, Scheidt-Nave C, et al. The effects of lifestyle, dietary dairy intake and diabetes on bone density and vertebral deformity prevalence: the EVOSstudy. Osteoporos Int; 12:688-698, 2001

28. Hasan N, Yaşar B, Tekin Ö, Masum Ş. Tek enerjili kantitatif BT yöntemiyle kemik metabolizması normal olan kadınlarda spinal trabeküler kemik mineral dansitesi ölçümü Tanısal ve Girişimsel Radyoloji, 8:274-278, 2000 